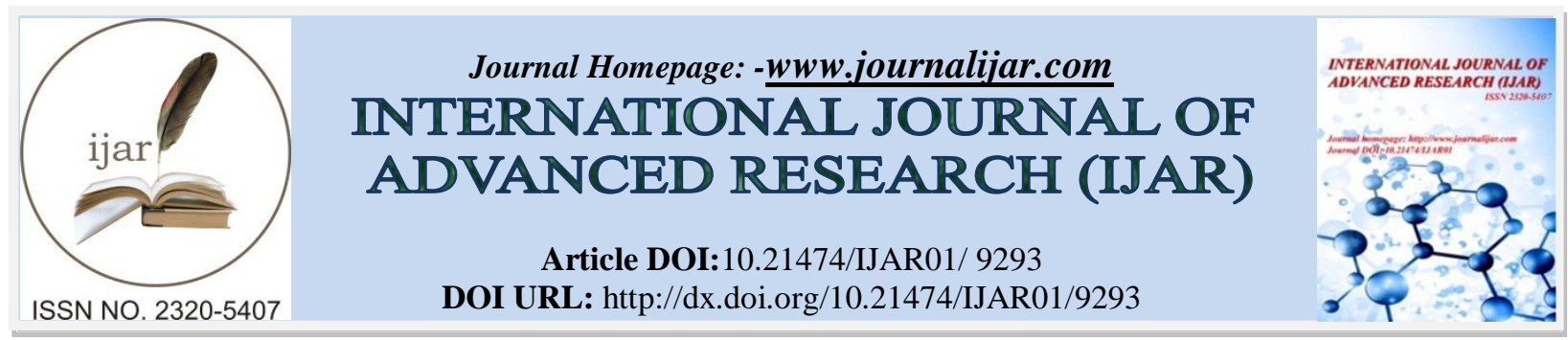

RESEARCH ARTICLE

\title{
EFFECT OF PSYCHO EDUCATIONAL PROGRAM ABOUT CONTROL OF SUICIDAL IDEATION AMONG PSYCHOTIC PATIENTS ON NURSING STAFF'S KNOWLEDGE AND PRACTICE.
}

\author{
Shaimaa Mosad El-Refaay ${ }^{1}$ and Prof.Dr. Mervat Hosny Shalaby ${ }^{2}$.
}

1. Assistant lecturer in Psychiatric and Mental health Nursing, Faculty of Nursing, Tanta University.

2. Professor of Psychiatric Nursing, Faculty of Nursing, Tanta University.

\section{Manuscript Info}

Manuscript History

Received: 15 April 2019

Final Accepted: 17 May 2019

Published: June 2019

Key words:-

Suicide, Psychiatric Nurses Knowledge ,Skills .

\section{Abstract}

Suicide is a tragic event with strong emotional repercussions for its survivors and for families of its victims. Suicide is considered a serious public health problem around the world, it is the major cause of death and morbidity worldwide. It is estimated that, approximately one million people died by suicide each year. Nurses are often on the front line positions for identifying and interviewing patients who are suicidal; therefore, nurses must be well trained in in the assessment of suicidal patients and know what to do when faced with a client who is actually suicidal. The aim of the study was to determine the effect of a psycho educational program about control of suicidal ideation among psychotic patients on a nursing staff 's knowledge and practice. The study sample consisted of 50 psychiatric nurses working at Tanta Mental Health Hospital having at least one year experience in the psychiatric field and providing direct care for psychotic patients .Aquasi-experimental design was utilized. Two tools were used for data collection: Tool (I): Nurse's knowledge about suicide Ideation questionnaire contain two parts ;Part1 )Structured Interview Schedule related to Socio-Demographic Data ,Part 2)Questions about suicide Ideation to assess nurse's knowledge about suicide. Tool (II):-An Observation Checklist for a Nurse's practice towards the suicidal patients :this was used to assess a nurse's skills regarding suicidal patients. The results revealed that there was a statistically significant improvement between the mean score of total knowledge and the skills score before intervention, immediately after and after three month of intervention. The study concluded : marked increase in the overall knowledge and skills of the nurses as the result of receiving an educational program about control of Suicidal Ideation among psychotic patients on nursing staff knowledge and practice. Recommendation: develop and implement educational programs for patient regarding control of Suicidal Ideation should be provided in a treatment program during a patient's hospitalization. 


\section{Introduction:-}

Suicide is a perplexing phenomenon that calls to mind very nature of human existence. It is a tragic event with strong emotional repercussions for its survivors and for families of its victims. It is away out of a problem or crisis that invariably causes intense suffering ${ }^{(1)}$.Suicide is associated with unwanted or unfulfilled need an emotional reaction of hopelessness and helpless, an ambivalent conflict between survival and unbearable stress, a narrowing of perceived option, and a need for escape ,the suicidal person's signal of distress ${ }^{(2,3)}$.

Suicide is the most violent form of self- destructive behavior .It is defined as a fatal act that is self-inflicted, consciously intended and is carried out with the knowledge that death is irreversible ${ }^{(4)}$. According to Tripodi and Bender (2006), Suicidal Ideation is "thoughts and planning" and often leads to a suicidal gestures of "self-harming behaviors", which may result in a' suicidal attempt (serious harm to self that could result in death with no intervention) and(may also lead to a completed suicide (harm to self resulting in death. ${ }^{(5,6)}$

Suicide is considered a serious public health problem around the world and is the major cause of death and morbidity worldwide. It is estimated that, approximately one million people died by suicide each year. For every completed suicide there are somewhere between 10 and 40 attempted suicides. The trend is upward, and it is estimated that the number of suicides will be 1.53 million in 2020 . The annual rate of suicide in Egypt was found to be 10 per100,000 with a high percentage in age group $15-44$ years olds ${ }^{(3,7)}$.

Moreover, studies have shown that the risk of suicide among patients in general hospital was three times higher than that found in a general population This may reflect a higher severity of conditions within hospital setting . Suicide has a strong association with psychiatric disorders ${ }^{(8,9)}$. Approximately $90 \%$ of suicide victims have a diagnosable psychiatric illness, usually major depression disorders, schizophrenia ,alcohol dependence, or personality disorders $(10)$

Working with suicidal patients can be an extremely challenging and stressful task for psychiatric nurses. Betz(2013) pointed out that many nurses don't respond well to working with suicidal individuals and avoid the topic of suicidality with their patients. The nurses often do not ask or fail to conduct suicide assessment with their clients. Perhaps nurses would be more likely to work with suicidal individuals or talk with patients about the issue of suicidality if they had more information and training ${ }^{(11,12)}$.

The role of psychiatric nurses is to help people to heal and recover, as well as to promote mental health ,and wellbeing. Consequently nurses can experience interpersonal conflicts in keeping some-one alive who doesn't want to live. In fact, psychiatric nurses who offer effective nursing care make the difference between life and death for suicidal patients. Each time someone dies by suicide it reinforces the need for nurses to enhance and advance the quality of nursing care provided, which includes working to design effective preventive strategies $\cdot(12,13)$

Nurses are often in the front lines for identifying and interviewing a patient who is suicidal. Nurses who provide twenty four hour care are in the best position to consistently meaningfully interact with patients and to help redirect suicidal behavior. A Nurse's availability and consistent visibility undoubtedly has an impact of suicidal patients. Furthermore, formal and informal plans of care must meet a variety of patients needs ${ }^{(13-15)}$

Nursing intervention has been generally be formulated based on a patient's need for constant monitoring and emotional support to maintain safety. Moreover, psychiatric nurses focus -primarily on human experience of distress and aims to promote healing and understanding, support and acceptance and through helping patients find meaning in their experience ${ }^{(16)}$.Gibb (2009) emphasizes the importance of communication in addition to safety and supportive intervention $^{(17)}$.

Therefore, nurses must be well trained in in the assessment of suicidal patients and know what to do when faced with a client who is actually suicidal .This would likely decrease a nurse's stress when working with suicidal patients and will be effective in decreasing injuries to patients as well as staff.

\section{The aim of this study is to:}

Determine the effect of a psycho-educational program regarding control of Suicidal Ideation among psychotic patients on nursing staff's knowledge and practice. 


\section{Research Hypothesis}

Staff nurse's knowledge and skills means score expected to increase post educational program about control of suicidal ideation among psychotic patients.

\section{Materials and Method:-}

Materials

Research design:

A quasi -experimental research design was used in this study.

\section{Research setting:}

The study was conducted at Tanta- Mental Health Hospital (inpatients ward) affiliated to ministry of Health and Population. It also provides health care services to three Governments, namely El - Gharbeya, El - Menofeya, and Kafr - El - Sheikh.

\section{Subjects:}

The subject was 50 psychiatric nurses( calculated using Epi-Info software) who work in the previous mentioned setting were selected randomly for this study. The subjects must have the following criteria:

at least one year experience in psychiatric field and currently providing direct care for psychotic patients.

Tools of the study:

The data will be collected by using the two tools :-

Tool I :Questionnaire on the Nurse' knowledge regarding suicide Ideation Part1 ) Structured Interview Schedule related to Socio-Demographic Data

This part was developed by the researcher and it includes items such as: age, sex, residence, educational level, marital status, years of experience at psychiatric nursing, previous suicide and prevention training.

\section{Part 2) Questioning a Nurse's knowledge about Suicide Ideation}

This part was developed by the researcher after a review of related literature ${ }^{(10-20)}$. It was used to assess nurse's knowledge about suicide. The questionnaire consisted of 37 items and was modified by the researcher to be 121 items presented in following nine sections:

1. Section 1 contains 4 items that measure sources of knowledge about concept of suicide

2. Section 2 contains 5 items that measure sources of knowledge about suicide rate of prevalence

3. Section 3 contains 15 items that measure sources of knowledge about suicide risk factors

4. Section 4 contains 19 items that measure sources of knowledge about psychiatric symptoms that lead to suicide

5. Section 5 contains 14 items that measure sources of knowledge about psychiatric disease causing suicide

6. Section 6 contains 8 items that measure sources of knowledge about methods of suicide

7. Section 7 contains 8 items that measure sources of knowledge about ethical principles in dealing with suicidal patients

8. Section 8 contains 8 items that measure sources of knowledge about treatment modalities for suicide

9. Section 9 contains 40 items that measure sources of knowledge about nursing role to prevent suicide

All questions had to be answered as a yes/no.

\section{Scoring System:}

Scoring was as the follows: For positive items, true statement $=1$, false statement $=0$.For negative items, true statement $=0$, false statement $=1$. The total score will be summated . The minimum score is 0 and the maximum score is 121 . The level of nurse's knowledge was categorized as the following:

1. Less than $50 \%=$ poor knowledge about suicide

2. From $50 \%$ to $75 \%=$ average level of knowledge

3. More than $75 \%=$ good level of knowledge

\section{Tool II:- Observation Checklist for Nurse's Practice towards a Suicidal Patients.}

The check list was developed by the researcher after a review of related literature ${ }^{(14-25)}$. It was used to assess a nurse's skills regarding suicidal patients. It consisted of 54 items that were modified by the researcher to be 84 items that were divided into 8 subscale :

1. Accept patient as individual, which contains 7 items. 
2. -Use therapeutic communication skill, which contains 23 items.

3. Early detection of suicide warning signs, which contains 7 items .

4. Maintain safe environment, which contains 18 items .

5. Help patient to cope with his problems, which contains 8 items .

6. Promote self esteem and hope for patient, which contains 7 items

7. Change patient negative thought, which contains 6 items .

8. Promote patient social interaction with other, which contains 8 items.

\section{Scoring system:}

Scoring was done as follows : There are two responses for each question :-(done=1, not done=2 ) ; the minimum score is 0 and the maximum score is 84 .

The level of a nurse's skills was categorized as the following:

1. Less than $50 \%=$ poor skill in treating suicidal patients.

2. From $50 \%$ to $75 \%$ =average level of skill in treating suicidal patients.

3. More than $75 \%=$ good level of skill in treating suicidal patients.

\section{Method:}

The steps in this study were conducted as follow:

1. An official letter was obtained from the director of Tanta Mental Health Hospital for data collection.

2. Ethical consideration:

1. Written consent was obtained from each nurse after explaining the purpose of the study in order to be participant.

2. Study subjects was informed that confidentiality and privacy was ensured.

3. Respecting the right of the study sample to be withdrawn from the study at anytime of data collection.

3. Tool I \& Tool II Nurse Knowledge about Suicide Ideation Questionnaire and Observation Checklist for Nurse's Practice Towards the Suicidal Patients were developed by the researcher after a review of literature

\section{Method of Scale Development:}

A theoretical rational deductive method of scale development (Clark andWatson,1995) was used for the Nurses Knowledge about Suicide Questionnaire( NKSQ) .Using this method, questionnaire items are borne out of personal experiences, relevant theories, and consultations with experts, and nursing participants working in psychiatric hospital. This is ensure the highest possible levels of construct validity (Holmbeck and Devine, 2009). (26,27) This method allowed for language and concepts unique to suicide knowledge to be written into the MSAQ items ,which increased the measure's targeted cultural appropriateness and face validity.

\section{Gathering Literature on suicidality}

To develop the Nurse Knowledge about Suicide Questionnaire, the researcher examined reviews of literature on psychiatric patient's suicide, collected articles and theories explaining nursing- roles for suicidal patients , and examined existing scales for suicidal risk. Those scales included Knowledge About Suicide Postvention (KSPV), Suicide Knowledge Quiz, SAD PERSONS Scale ,Suicide Ideation Questionnaire and Suicide Intervention Response Inventory 2 (SIRI 2). After analysis of the contents of each scale , the researcher found some items related to suicide definition, risk factors and protective factors, incidence and suicide treatment .However, there were no specific items related to psychiatric patient suicide and no items to assess nurse's knowledge about suicide, in addition to not covering all risk factors for psychiatric patient suicide and warning signs for suicide .Therefore, it was essential to develop a specific tool to assess a nurse's knowledge about patient's suicides. Based on the review of literature $^{(10-20)}$ and the previous analysis of the contents of the scale mentioned above, the researcher discussed the essential components of NKSQ with a group of experts; researchers organized themes for items development which included -relation to concept of suicide, suicide prevalence rate, suicide risk factors ,causes of suicide ,method of suicide, ethical principles for dealing with suicidal patients , and treatment of suicide and nursing role in suicide prevention within screening questionnaire. Most experts suggested to write positive, and negative statements , and some statements were written to precisely assess nurse knowledge about suicide. The preliminary version of questionnaire consisted of 60 items were grouped into 6 conceptual categories (all questions had to be answered as a yes/no). All items were constructed and validated in Arabic language . 


\section{Expert Panel Review}

A panel of ten expert viewers was consulted to further refine the item pool of the NKSQ. Reviewers consisted of 4 members of academic staff who all held an advanced degree in psychiatric nursing and were considered subject matter experts in the fields of clinical psychiatric nursing , as well as 2 professors of psychiatry and neurology who were experts in clinical psychology and suicidology. The viewers were asked to rate the importance and fit (to 6 conceptual categories ) each of the 30 preliminary NKSQ items according to a five-point scale $(0$ to 4 , where $0=$ completely unimportant and $4=$ completely important).The experts were required to give the corresponding score in terms of the importance of items .After reviewing all items considered relevant to the aim of study, suggestions were made regarding the exclusion of 5 items and addition of new 25 items which grouped into the following concepts ( psychiatric symptoms causing suicide and,psychiatric diseases causing suicide) .Some items were modified .

\section{Final Version of the NKSQ}

After a final revision by the panel of expert, the author modified some statements and wrote an additional two conceptual categories ( psychiatric symptoms causing suicide, and psychiatric diseases causing suicide) for inclusion in the NKSQ. Hence, the final complete version of the NKSQ consisted of 84 items which were grouped into 8 conceptual categories. Before the researcher distributed the questionnaire to the proposed sample ,all the items in the questionnaire were written without the title of the conceptual categories, specifically ordering the statement to avoid leading the answer to the participants.

\section{Pilot study:}

A pilot study was conducted on 20 nurses who worked at Tanta Mental Health Hospital (inpatients ward) and affiliated to the ministry of Health and Population in Egypt after being approved to test the feasibility and applicability of the NKSQ, as well as determining possible obstacles that might be encountered during the period of data collection .Afterwards they were asked to provide their comments about problems in completing it, including whether it was clear and understandable, and also whether the content was complete and relevant. Participants filled out the questionnaires through interviews and any vague statement was clarified by the researcher. After its implementation and according to the results, some statements in the area of (ethical principles for dealing with suicidal patients) needed rewording. Some statements in the area of (a nurse's role in suicide prevention) needed rewording as well as some statements in the same category needed to be (replaced with more simple statements. Necessary modification was done after discussions with experts and 40 nurses who worked in previous settings were retested to assess reliability of the tool. After these were produced, the final version of the tool to test validity and reliability was created.

\section{Final Revised Version of the NKSQ:}

After conducting pilot study and retest questionnaire on participants to ascertain its reliability ,the final version of NKSQ was composed of 84 items which were grouped into 8 conceptual categories , and a scoring system was calculated as the following: For positive items, a true statement $=1$, a false statement $=0$. For negative items, a true statement $=0$, a false statement $=1$. The total score is then summated ; the minimum score is 0 and the maximum score is 84 . While further research is needed to validate the screening tool, the findings provide a useful preliminary starting point for nurses to assess knowledge about suicide

\section{Psychometric Properties of NKSQ: Validating the Model: \\ Face validity}

Face validity is the extent to which an instrument fits the expectation. This is usually determined by enlisting an expert panel rather than by formal statistical methods (Peat 2001). According to Peat good face validity is essential because it is a measure of the expert perception of the acceptance, appropriateness and precision of an instrument. In this study face validity was obtained through expert perceptions, an expert panel, comprising professor in clinical psychiatry, and some senior psychiatrists. Early draft versions of the instrument were scrutinized for face validity and suggested changes were incorporated. ${ }^{(28)}$

\section{Content validity}

Content validity is the extent to which the items in a questionnaire or instrument adequately cover the domain under investigation (Peat 2001). As with face validity, this is judged by experts rather than by formal statistical analyses. Content validity was initially considered at the same time as the face validity. Thus, the expert panel, was asked to 
judge the instrument. The opinion of the expert panel was that, some modification was required as two conceptual areas were included (psychiatric symptoms causing suicide, psychiatric disease causing suicide) and some items were modified to prevent obvious omissions in the instrument.

\section{Reliability}

1. Data analysis Data was analyzed using SPSS18.0 and AMOS 18.0 software. Descriptive statistics were used to outline the demographic characteristics. Cronbach's Alpha coefficient was computed for internal consistency reliability, and intraclass correlation coefficient (ICC) was used to evaluate test-retest reliability.

2. The Cronbach's Alpha coefficient was 0.817 , and it was slightly changed once some items were added to questionnaire .To evaluate test-retest reliability, 40 psychiatric nurses were re measured after 2 weeks, and the intra class correlation coefficient was 0.765 .

3. All tools were tested for content validity by five experts in the field of psychiatric nursing to ascertain the appropriateness of items for measuring what they are supposed to measure.

4. Internal consistency of the study tools I \& II was done by means of Cronbach's Alpha coefficient which yielded values of $r=0.9421-r=0.9325$ respectively.

5. A pilot study was carried out to ascertain the clarity and applicability of the study tools, and to identify obstacles that might be faced during data collection. It was done on 10 nurses; who were later excluded from the actual study. After implementation of the pilot study and according to its results, some statements in the subscale of (ethical principles for dealing with suicidal patients ) ( No 4,7,8) needed rewording ,some statement in the subscale of (a nurse's role in suicide prevention ) (No 8,14,17, 23,26,33) needed rewarding .Lastly, some statements in the same subscale (No 1,7,36,41) were replaced with simpler statements. Necessary modification was done after discussions with experts and were retested on 10 nurses who worked in previous setting to assess the reliability of the tool . After these producers, the final version of the instrument to test validity and reliability was created.

6. Actual study was divided into four phases:

\section{Assessment Phase:-}

1. The researcher performed pre-tests to the selected subjects by application tool I \&tool II.

2. Tool I (Nurse's Knowledge about Suicide Ideation Questionnaire)was distributed the nurses and they were asked to fill in answers the presence of the researcher for necessary clarification.

3. Tool II (Observation Checklist for Nurse's Practice toward Suicidal Patients) was applied by indirect observation to each nurse during their contact with patients and perform nursing care .The time of the observation was at least 10 minutes in the morning shift for 3 times because a number of nurses were more available in the morning shifts than others.

4. Before the beginning of the program, the researcher fixed a meeting time with the participants, on Sundays, or Mondays (every other weeks).

\section{Planning Phase:-}

A Psycho- educational program was developed by the researcher based on the results from the pre-test and from a review of literature ${ }^{(15-22)}$. The over all goal and the objectives of the program were formulated as follws:

\section{Overall Goal:}

The psycho-educational program was developed to enhancing the knowledge and skills of psychiatric nurses working at Tanta mental health hospital toward suicidal patients

\section{Objectives of the Program}

At the end of the program, students should be able to:

1. Define the concept of suicide.

2. Mention the prevalence rate of suicide.

3. Identify risk factors of suicide.

4. Explain psychiatric symptoms and psychiatric diseases causing suicide and apply appropriate nursing care for them.

5. Recognize ethical principles when dealing with suicidal patients.

6. Apply communication techniques when dealing with suicidal patients.

7. Identify different treatment modalities for suicide.

8. Apply nursing role when care for suicidal patients . 
9. The researcher prepared for sessions starting with the creation of the suitable environmental condition for conducting the program. At Tanta Mental Health Hospital, the conference class was used for discussion, explanation, and demonstration. At Tanta University Hospital, the program was conducted in nurses' room.

1. The researcher prepared videos, pictures and power point presentations to be used in the educational program.

2. A booklet was developed and was distributed to every nurse for enforcement and as a reference .

3. The researcher, modified a number of program sessions based on the assessment phase to be increase for a total of 12 sessions instead of 8 sessions.

Implementation Phase:-

A psycho- educational program was implemented by the researcher after review of related literature and its content:

1. First session: Was an introductory session that emphasized acquaintance between the nurses as well as the researcher to obtain verbal consent, and also to explain of the program's purpose ,and objectives and its schedule. This session last for about one hour.

2. Second session: Covered these topics:-" The meaning of suicide ,prevalence, causes ,risk factors for suicide ,and methods of suicide. " This session lasted for about two hours. The researcher divided this session as follows :the first hour was the explanation of the concept and prevalence of suicide followed by a 15 minutes breaks. After that, the researcher continued with risk factors for suicide, and methods of suicide supported by videos and pictures.

3. Third session: Covered the topics:-" Psychiatric disorders associated with suicide " This session last for about two hours with 15 minutes breaks.

4. Fourth session: Covered these topics: "Psychiatric symptoms associated with suicide, and appropriate nursing care." This session lasted for about two hours with 15 minutes breaks.

5. Fifth session: Covered the topics:" Ethical responsability of nurses toward suicide patients " This session lasted for about two hours with 15 minutes breaks. The researcher in this session asked nurses about ethical clinical situations facing them in a clinical setting and discuss principles to solve these ethical situations.

6. Sixth session: Covered the topics:" Therapeutic communication techniques for nurses dealing with suicidal patients and their application. " This session lasted for about two hours. The researcher divided the session into two parts; the first part deal with explanations of different communication techniques for dealing with suicidal patients, then after 15 minutes breaks nurses were introduced to various videos about communication techniques and performed application of these techniques through distribution of clinical situations to nurses.

7. Seventh session : Covered the topics:" Psychiatric nursing roles for suicidal patients including the process of assessment and intervention". This session lasted for about two hours with a 15 minutes breaks. .The researcher divided nursing roles into two sessions. In this session ,the researcher started by asking nurses about their intervention with suicide patients and discussed common mistakes in their interventions .

8. Eighth session: Covered the topics:" psychiatric nursing roles for suicidal patients including process of assessment and intervention. "This session last for about two hours with 15 minutes break. In this session for explanation of nursing intervention suicidal patients .At the end of session ,the researcher ask nurses to write complete nursing care plan for actual cases meeting them in their work

9. Ninth session: Covered the topics:" treatment modalities that may be used for persons at risk for suicide. " This session lasted for about two hours with a 15 minutes breaks.

10. Eleventh session: Covered the topics:" role play for nurses that encourage them to explore own concern toward suicidal patients and clarify any misinterpretation " This session lasted for about three hours with 15 minutes breaks .The researcher distributed duties of the role- play \& its script's to the nurses and discussed the character of each actor before acting in the role -play. The researcher demonstrated role- play with one nurse first, then discussed the situation of role play with the other nurses and clarified any misinterpretation. After acting out a role- play, the researcher gathered the nurses into a discussion of the played roles and gave constructive feedback to them. After acting a role-play, the researcher shared the nurses into a discussion of the played roles and gave constructive feed back to them.

11. Twelefth session: Termination of the program, immediate test, distribute the booklet about suicide prevention.

12. The program was offered through twelve sessions. These sessions was presented through lecture and discussion , visual -aids and handouts. The researcher informed the nurses about the title of the video or the image before its presentation then discussed it and offered a feed back.

13. The researcher started each session by asking the nurses about what was taught in the previous session and ended it by summarizing what was given during the present session. This took about 10 minutes each session.

14. The total number of the study subject were divided into 5subgroups. Each sub group was composed of 10 nurses. 
15. Each sub group attended twelve -session. This sessions were scheduled as 4 sessions per week - in the morning shifts for a duration of about 3 weeks. Total sessions for all nurses was take about 15 weeks.

16. The researcher distributed booklets to the nurses at the end of the program as a source of reference.

\section{Evaluation Phase:}

The evaluation of the effect of psycho -educational program was done by using tool I, and tool II on psychiatric nurses and performed the as same as pre- test. This was done as follows:

Immediately after implementation of the psycho-educational program (post- intervention 1).

Three months later after implementation of the psycho- educational program (post -intervention 2).

The study was conducted in April 2017 and finished in October 2018.

\section{Statistical Analysis:}

The collected data was organized, tabulated and statistically analyzed using SPSS version 19 (Statistical Package for Social Studies) created by IBM, Illinois, Chicago, USA. For numerical values, the range mean and standard deviations were calculated. The differences between two mean values were compared using student's t test. Differences of mean values between more than two groups were tested by analysis of variance $(F)$ test ,followed by a Bonferroni test whenever a result was significant. The relations between quantitative variables were tested by Pearson's correlation coefficient $(r)$. The level of significance was adopted at $p<0.05$. For categorical variables, the numbers and percentages were calculated and the associations and between variables were tested by chi square $\left(\mathrm{X}^{2}\right)$.

\section{Results:-}

Table (1):-Shows that most patients were male (76\%.) The highest percentage of the studied patients had an age range between 30to 40 years were $60 \%$ With mean $37.30+11.42$. Regarding the marital status of nurses $80 \%$ of the subjects were married , and only $2 \%$ were divorced . In relation to the level of education, the table revealed that( $30 \%$ )of the studied nurses graduated from secondary school of nursing, while only (2\%) had a master or doctoral degree in nursing.

The table also presented thats $40 \%$ of the studied nurses had experience in psychiatric nursing for more than 10 years . Concerning the patients' occupational status, it was observed that $56 \%$ of the studied subjects were unemployed , and only $4 \%$ of them were retired. In relation to previous training on suicide prevention, the table reveals that $74 \%$ of the studied nurses had not received previous training on suicide prevention

Table (2):- Revealed that there was no statistically significant relation between a nurse's concept of suicide subscale before, immediately after, and after three months from implementation of the educational program in which (Pvalue $>0.005)$.

Table (3):- Shows that, Where studied nurses had a mean score of suicide prevalence subscale before program $(.5600+0.15649)$, while this level became high immediately and three months after program $(.4120+.16860 \& .4520+.22789$ respectively). The results revealed that there is a highly statistic relation between a nurse's prevalence of suicide subscale before and after and follow up in which $(\mathrm{P}-\mathrm{value}=0.000)$.

Table (4):- Revealed that risk factors for suicide subscale before, which was significantly different from immediately after and at follow up in which $\left(\mathrm{P}\right.$-value $\left.=0.001^{*}\right)$. Where studied nurses had a mean score of risk factors for suicide subscale before program $(4.56+2.09)$, this level became high immediately and three months after program $(8.98+1.68 \& 8.30+2.04$ repectively $)$

Table (5):- Revealed that the studied nurses had a mean score of psychiatric symptoms causing subscale before program $(6.28+2.68)$, while this level became high immediately and three months after the program $(12.10+1.20 \& 10.86+2.01$ respectively). The results revealed that before was significantly different from immediately after and at follow up and immediately after significantly different form at follow up in which ( $\mathrm{P}$-value $=0.001 *$ ).

Table (6):- Revealed a comparison of psychiatric disease causing suicide a mean score within study sample during pre and post, pre and follow up the study. As it was found that the mean score about psychiatric diseases causing 
suicide was highly improved after conducting the program than before as $(\mathrm{P}$-value $=0.000)$. Where studied nurses

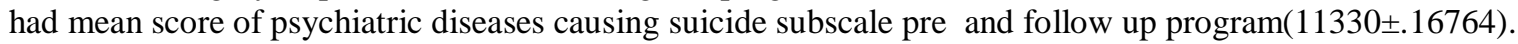

Table (7):- Shows that the nurses had a mean score of psychiatric symptoms causing subscale before program $(.4100+.25882)$, while this level became high immediately and three months after program $(.8275+.09412 \& .7225+.19281$ respectively). The results revealed that before was significantly different from immediately after and at follow up and immediately after significantly different from at follow up in which (Pvalue $=0.00^{*}$ )

Table (8):-Revealed that there was high statistically significant relation between nurses with ethical principles subscale before, immediately after, and after three month from implementation of the educational program in which $\left(\mathrm{P}\right.$-value $\left.<0.005^{*}\right)$. Where studied nurses had a mean score of ethical principles subscale before program $(4.62+0.92)$, this level became high immediately and three months after program $3.10+0.89 \& 3.54+1.30$ respectively)

Table (9):- Showed that there is no statistically significant relation between nurse's concept of suicide subscale prepost \& pre-follow up after implementation of the educational program in which ( $\mathrm{P}$-value $>0.05$ ), while there is significant relation between nurses concept of suicide subscale post-follow up in which(P-value $=.088)$.

Table (10):-Showed that there is a highly statistically significant relation between the role of nurses in suicide prevention subscale pre and immediately after implementation of the educational program in which (Pvalue $=<0.05$ ). However ,there is no statistically significant relation between role of nurses in suicide prevention subscale pre and at follow up after implementation of the educational program in which (P-value=0.411).

Table (11): Illustrated that the total mean knowledge score of studied nurses had improved immediately after implementation of the educational program. Where studied nurses had a total mean score regarding the role of nurse in suicide prevention before program $(44.7444+5.82837)$, this level became high immediately after program $(54.2355+3.72401 \& 62.18+5.05$ respectively). It is evident also that there is no statistically significant relation between total mean knowledge score of studied nurses before and after three months from implementation of the educational program

Table (12):-Demonstrated that the nurses had a mean score of caring behavior subscale (accept patients) skill before program $(.2343+.21744)$, while this level became high immediately and three months after program $(.8514+.15798 \& 6371+.30161$ respectively). The results revealed that there is a highly statistically significant relation between nurses performance subscale (accept patient) skill before, immediately after, and after three months from implementation of the educational program in which $(\mathrm{P}-\mathrm{value}=0.000 *)$.

Table (13):- Revealed that there is a highly statistically significant relation between nurses' performance subscale (therapeutic communication) skill before and post, pre and follow up \& post and follow up implementation of the educational program in which ( $\mathrm{P}$-value $=0.000 *$ ). Where studied nurses had a mean score of nurse's performance subscale (therapeutic communications) skill before program $(.2942+07505)$, while this level became high immediately and three months after program $(07505+12266 \& .4931+.11517$ respectively).

Table (14):- Illustrated that the mean score among nurses' performance subscale (early detection of suicide attempts) skill was highly improved after conducting the program than before as $(\mathrm{P}$-value $=0.000)$. Where studied nurses had a mean score of performance subscale (early detection of suicide attempts) skill pre-follow up program is $(.28571+.26452)$ also studied nurses had a mean score of nurses' performance subscale $(4.02+1.62)$ skill pre-post program is $(.50000+.23492)$.

Table (15):- Showed that there is highly statistically significant relation between nurses' performance subscale (safe environment) skill before, immediately after, and after three months from implementation of the educational program in which $(\mathrm{P}$-value $=0.001 *)$. Where studied nurses had a mean score of caring behavior subscale (safe environment) skill before program $(.1733+.17911)$, this level became high immediately and three months after program $(.6044+.17911 \& .4500+26016$ respectively). 
Table (16):- Revealed that the studied nurses had a mean score of caring behavior subscale (help patient to cope) skill before program $(1.08+1.93)$, while this level became high immediately and three months after the program $(4.52+1.61 \& 2.78+1.71$ respectively).The results revealed that there is a highly statistically significant relation between nurses of caring behavior subscale (help patient to cope) skill before, immediately after, and after three months from implementation of the educational program in which $\left(\mathrm{P}-\right.$ value $\left.=0.000^{*}\right)$.

Table (17):- Illustrated that there is highly statistically significant relation between nurses caring behavior subscale (promote self esteem) skill before and post, pre and follow up and post and follow up implementation of the educational program in which $(\mathrm{P}$-value $=0.000 *)$.

Table(18):- Showed that there is a highly statistically significant relation between nurses' performance subscale (change negative thoughts) skill before, immediately after, and after three month from implementation of the educational program in which $\left(\mathrm{P}\right.$-value $\left.=0.000^{*}\right)$. Where the studied nurses had a mean score of caring behavior subscale (change negative thoughts) skill before program $(.0300+.07292)$, this level became high immediately and three months after program $(3.24+.20909$ and $3200+21518$ respectively).

Table (19):- Demonstrated that there is a highly statistically significant relation between nurses performance subscale (promote social interaction) skill before, immediately after, and after three month from implementation of the educational program in which $\left(\mathrm{P}\right.$-value $\left.=0.000^{*}\right)$. Where the studied nurses had a mean score of performance subscale (promote social interaction) skill pre-follow up program is.(35500+..22779), also the studied nurses had a mean score of nurse's performance subscale skill pre-post program is $(.51000+.24333)$.

Table (20):- Illustrated that there is a highly statistically significant relation between total mean score of the studied nurses' performance before, immediately after, and after three months from implementation of the educational program in which $\left(\mathrm{P}\right.$-value $\left.=0.000^{*}\right)$. Where the studied nurses had a total performance score before program $(14.4373+11.03578)$, this level became high immediately and three months after program $(60.9925+12.57687 \& 41.9589+16.47868$ respectively).

Tables (22):- Indicated that there was a negative and non-significant relation pre, post and follow up program regarding their total performance score and academic qualification in the field of suicide prevention where $(\mathrm{P}=0.017)$. Also a negative and non-significant relation was found between their performance score and previous training in suicide prevention where $(\mathrm{P}=0.903)$

Table (23):- Showed that there was a statistically significant relationship between the nurses' total performance score and total knowledge score immediately after implementation of the program as P-value $=(0.045)$ and $\mathrm{r}$ $=(0.285)$. Also there was a statistically significant relationship between the nurses' total performance score and total knowledge score at follow up of implementation of the program as $\mathrm{P}$-value $=(0.009)$ and $\mathrm{r}=(0.365)$.

Table 1:-Distribution of studied subjects according to their socio-demographic and clinical characteristics.

\begin{tabular}{|c|c|c|}
\hline Variables & $\begin{array}{c}\text { Number } \\
\text { (n=50) }\end{array}$ & \% \\
\hline Age in Years & 15 & 30.0 \\
$20-$ & 30 & 60.0 \\
$30-$ & 5 & 10.0 \\
$40-$ & \multicolumn{2}{|c|}{$\mathbf{3 0 . 9 8 + 6 . 1 3}$} \\
\hline Range & 12 & 34.0 \\
\hline Mean+SD & 38 & 76.0 \\
\hline Sex & 7 & 14.0 \\
Male & 40 & 80.0 \\
Female & 1 & 2.0 \\
\hline Marital Staus & 2 & 4.0 \\
Single & \multicolumn{2}{|c|}{} \\
Married & Widow & \\
Divorced & \multicolumn{2}{|c|}{} \\
\hline Residence & & \\
\hline
\end{tabular}




\begin{tabular}{|c|c|c|}
\hline Urban & 17 & 34.0 \\
Rural & 33 & 66.0 \\
\hline Education level & \multicolumn{2}{|c|}{} \\
Nursing diploma & 21 & 42.0 \\
Bachelor of nursing & 12 & 24.0 \\
Secondary school of nursing & 17 & 34.0 \\
\hline $1-$ & 14 & 28.0 \\
$6-10$ & 16 & 32.040 .0 \\
$>10$ & 20 & \\
& \multicolumn{2}{|c|}{$\mathbf{6 . 9 4 + 4 . 1 3}$} \\
\hline Range & $1-13$ & \\
\hline Mean+SD & \multicolumn{2}{|}{} \\
\hline Previous training in suicide prevention & \multicolumn{2}{|c|}{} \\
Yes & 13 & 74.0 \\
No & 37 & \\
\hline
\end{tabular}

Table 2:-Distribution of the studied nurses in relation to their mean score regarding the concept of suicide subscale pre, post and follow up of the implementation of training program

\begin{tabular}{|c|c|c|c|c|c|c|c|c|c|}
\hline \multirow{2}{*}{$\begin{array}{c}\text { Knowledge about } \\
\text { suicide }\end{array}$} & \multicolumn{3}{|c|}{ Comp. } & \multicolumn{2}{c|}{ Difference } & \multicolumn{2}{c|}{ Paired T-test } \\
\cline { 2 - 7 } & Mean & \pm & SD & & Mean & SD & t & P-value \\
\hline $\begin{array}{c}\text { Concept } \\
\text { of } \\
\text { suicide }\end{array}$ & Pre & .4900 & \pm & .22565 & Pre-Post & .02000 & .31880 & .444 & 0.072 \\
\cline { 2 - 9 } & $\begin{array}{c}\text { Post } \\
\text { up }\end{array}$ & .5100 & \pm & .17467 & Pre-Follow up & .05500 & .29142 & 1.335 & 0.784 \\
\hline
\end{tabular}

Table 3:-Distribution of the studied nurses in relation to their mean score of prevalence of suicide subscale pre, post , and follow up of the implementation of the training program

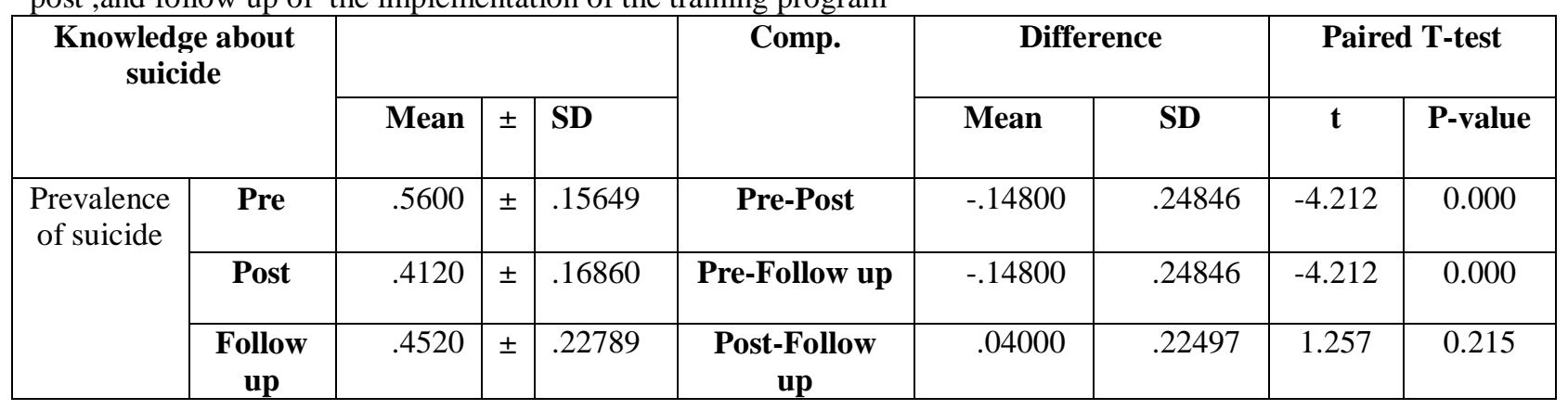

Table 4:- Distribution of the studied nurses in relation to their mean score of risk- factors for suicide subscale pre, post, and follow up of the implementation of the training program.

\begin{tabular}{|c|c|c|c|c|c|c|c|c|c|}
\hline \multicolumn{2}{|c|}{$\begin{array}{c}\text { Knowledge about } \\
\text { suicide }\end{array}$} & \multicolumn{3}{|c|}{ 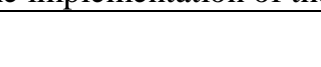 } & \multirow[t]{2}{*}{ Comp. } & \multicolumn{2}{|c|}{ Difference } & \multicolumn{2}{|c|}{ Paired T-test } \\
\hline & & Mean & \pm & SD & & Mean & SD & $\mathbf{t}$ & P-value \\
\hline \multirow{3}{*}{$\begin{array}{l}\text { Risk factors } \\
\text { for suicide }\end{array}$} & Pre & .3257 & \pm & . .14938 & Pre-Post & .31571 & .22546 & 9.902 & 0.000 \\
\hline & Post & .6414 & \pm & .12030 & Pre-Follow up & .26714 & .20296 & 9.307 & 0.00 \\
\hline & $\begin{array}{l}\text { Follow } \\
\text { up }\end{array}$ & .5929 & \pm & ..14592 & $\begin{array}{l}\text { Post-Follow } \\
\text { up }\end{array}$ & -.04857 & .15165 & -2.265 & 0.028 \\
\hline
\end{tabular}


Table 5:-Distribution of the studied nurses in relation to their mean score of treatment of psychiatric symptoms causing suicide subscale pre, post, and follow up of the implementation of the training program

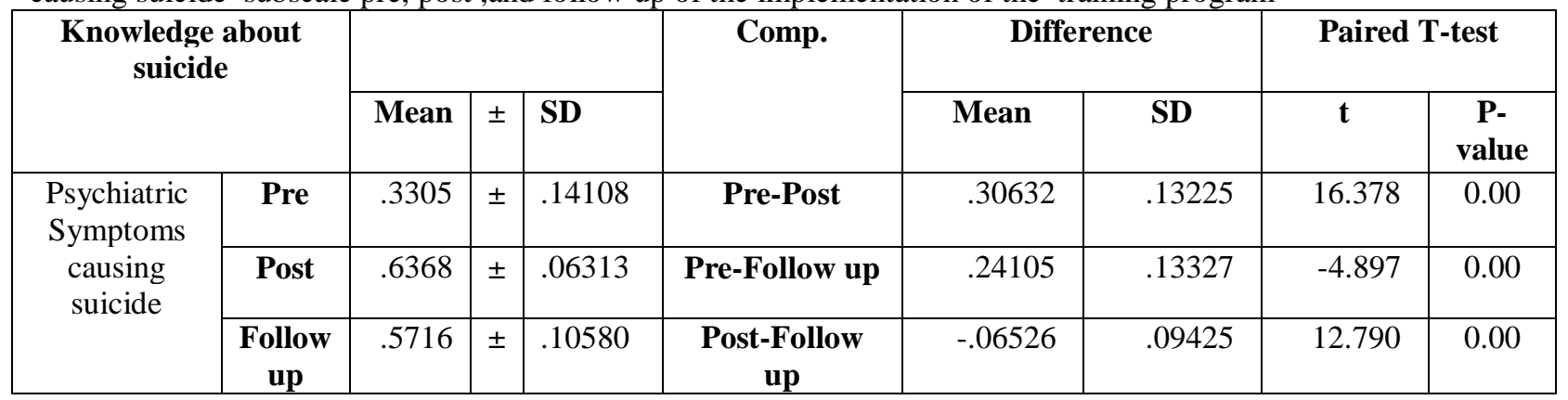

Table 6:-Distribution of the studied nurses in relation to their mean score of psychiatric diseases causing suicide subscale pre, post , and follow up of the implementation of the training program

\begin{tabular}{|c|c|c|c|c|c|c|c|c|c|}
\hline \multicolumn{2}{|c|}{$\begin{array}{l}\text { Knowledge about } \\
\text { suicide }\end{array}$} & \multirow[b]{2}{*}{ Mean } & \multirow[b]{2}{*}{ \pm} & \multirow[b]{2}{*}{ SD } & \multirow[t]{2}{*}{ Comp. } & \multicolumn{2}{|c|}{ Difference } & \multicolumn{2}{|c|}{ Paired T-test } \\
\hline & & & & & & Mean & SD & $\mathbf{t}$ & P-value \\
\hline \multirow{3}{*}{$\begin{array}{c}\text { Psychiatric } \\
\text { diseases } \\
\text { causing } \\
\text { suicide }\end{array}$} & Pre & .3100 & \pm & .11235 & Pre-Post & .12857 & .11724 & 7.755 & 00.0 \\
\hline & Post & .4386 & \pm & .11724 & Pre-Follow up & .11330 & .16764 & 4.779 & 0.00 \\
\hline & $\begin{array}{c}\text { Follow } \\
\text { up }\end{array}$ & .4233 & \pm & .14948 & Post-Follow up & -.01527 & .16586 & -.651 & 0.518 \\
\hline
\end{tabular}

Table 7:- Distribution of the studied nurses in relation to their mean score of suicide methods subscale pre, post , and follow up of the implementation of the training program.

\begin{tabular}{|c|c|c|c|c|c|c|c|c|c|}
\hline \multicolumn{2}{|c|}{$\begin{array}{c}\text { Knowledge about } \\
\text { suicide }\end{array}$} & \multirow[b]{2}{*}{ Mean } & \multirow[b]{2}{*}{ \pm} & \multirow[b]{2}{*}{ SD } & \multirow[t]{2}{*}{ Comp. } & \multicolumn{2}{|c|}{ Difference } & \multicolumn{2}{|c|}{ Paired T-test } \\
\hline & & & & & & Mean & SD & $\mathbf{t}$ & P-value \\
\hline \multirow{3}{*}{$\begin{array}{l}\text { Suicide } \\
\text { methods }\end{array}$} & Pre & .4100 & \pm & .25882 & Pre-Post & .41750 & .25078 & 11.772 & 0.00 \\
\hline & Post & .8275 & \pm & .09412 & Pre-Follow up & .31250 & .24776 & 11.772 & 0.00 \\
\hline & $\begin{array}{l}\text { Follow } \\
\text { up }\end{array}$ & .7225 & \pm & .19281 & Post-Follow up & -.10500 & .19457 & -3.816 & 0.00 \\
\hline
\end{tabular}

Table 8:-Distribution of the studied nurses in relation to their mean score of ethical principles dealing with suicide subscale pre, post, and follow up of the implementation of the training program

\begin{tabular}{|c|c|c|c|c|c|c|c|c|c|}
\hline \multicolumn{2}{|c|}{$\begin{array}{l}\text { Knowledge about } \\
\text { suicide }\end{array}$} & \multirow[b]{2}{*}{ Mean } & \multirow[b]{2}{*}{ \pm} & \multirow[b]{2}{*}{ SD } & \multirow[t]{2}{*}{ Comp. } & \multicolumn{2}{|c|}{ Difference } & \multicolumn{2}{|c|}{ Paired T-test } \\
\hline & & & & & & Mean & SD & $\mathbf{T}$ & P-value \\
\hline \multirow{3}{*}{$\begin{array}{c}\text { Ethical } \\
\text { principles } \\
\text { in dealing } \\
\text { with } \\
\text { suicide }\end{array}$} & Pre & .5775 & \pm & .11542 & Pre-Post & -.19000 & .15411 & -8.718 & 0.000 \\
\hline & Post & .3875 & \pm & .11080 & Pre-Follow up & -.13500 & .15535 & -6.145 & 0.000 \\
\hline & $\begin{array}{c}\text { Follow } \\
\text { up }\end{array}$ & .4425 & \pm & .16212 & $\begin{array}{c}\text { Post-Follow } \\
\text { up }\end{array}$ & .05500 & .17158 & 2.267 & 0.028 \\
\hline
\end{tabular}


Table 9:-Distribution of the studied nurses in relation to their mean score treatment of suicide subscale pre, post, and follow up of the implementation of the training program

\begin{tabular}{|c|c|c|c|c|c|c|c|c|c|}
\hline \multicolumn{2}{|c|}{$\begin{array}{c}\text { Knowledge about } \\
\text { suicide }\end{array}$} & \multirow[b]{2}{*}{ Mean } & \multirow[b]{2}{*}{ \pm} & \multirow[b]{2}{*}{ SD } & \multirow[t]{2}{*}{ Comp. } & \multicolumn{2}{|c|}{ Difference } & \multicolumn{2}{|c|}{ Paired T-test } \\
\hline & & & & & & Mean & SD & $T$ & P-value \\
\hline \multirow{3}{*}{$\begin{array}{l}\text { Treatment } \\
\text { of suicide }\end{array}$} & Pre & .5175 & \pm & .13365 & Pre-Post & -.03250 & .14465 & -1.589 & 0.119 \\
\hline & Post & .4850 & \pm & .09987 & Pre-Follow up & .00750 & .17930 & .296 & 0.769 \\
\hline & $\begin{array}{c}\text { Follow } \\
\text { up }\end{array}$ & .5250 & \pm & .16366 & $\begin{array}{l}\text { Post-Follow } \\
\text { up }\end{array}$ & .04000 & .16257 & 1.740 & 0.088 \\
\hline
\end{tabular}

Table 10:-Distribution of the studied nurses in relation to their mean role of nurses in suicide prevention subscale pre, post, and follow up of the implementation of the training program.

\begin{tabular}{|c|c|c|c|c|c|c|c|c|c|}
\hline \multicolumn{2}{|c|}{$\begin{array}{c}\text { Knowledge about } \\
\text { suicide }\end{array}$} & \multirow[b]{2}{*}{ Mean } & \multirow[b]{2}{*}{ \pm} & \multirow[b]{2}{*}{ SD } & \multirow[t]{2}{*}{ Comp. } & \multicolumn{2}{|c|}{ Difference } & \multicolumn{2}{|c|}{ Paired T-test } \\
\hline & & & & & & Mean & SD & $\mathbf{T}$ & P-value \\
\hline \multirow{3}{*}{$\begin{array}{c}\text { Role of } \\
\text { nurse in } \\
\text { suicide } \\
\text { prevention }\end{array}$} & Pre & .5058 & \pm & .06968 & Pre-Post & -.03451 & .07165 & -3.406 & 0.001 \\
\hline & Post & .4712 & \pm & .03731 & Pre-Follow up & -.00976 & .08317 & -.829 & 0.411 \\
\hline & $\begin{array}{l}\text { Follow } \\
\text { up }\end{array}$ & .4960 & \pm & .08517 & $\begin{array}{c}\text { Post-Follow } \\
\text { up }\end{array}$ & .02476 & .08154 & 2.147 & 0.037 \\
\hline
\end{tabular}

Table 11:-Distribution of the studied nurses in relation to their mean role of nurses in suicide prevention subscale pre, post and follow up of the implementation of the training program

\begin{tabular}{|c|c|c|c|c|c|c|c|c|c|}
\hline \multicolumn{2}{|c|}{$\begin{array}{c}\text { Knowledge about } \\
\text { suicide }\end{array}$} & \multicolumn{3}{|c|}{ (n) } & \multirow[t]{2}{*}{ Comp. } & \multicolumn{2}{|c|}{ Difference } & \multicolumn{2}{|c|}{ Paired T-test } \\
\hline & & Mean & \pm & SD & & Mean & SD & $\mathbf{T}$ & P-value \\
\hline \multirow{3}{*}{$\begin{array}{c}\text { Role of } \\
\text { nurse in } \\
\text { suicide } \\
\text { prevention }\end{array}$} & Pre & .5058 & \pm & .06968 & Pre-Post & -.03451 & .07165 & -3.406 & 0.001 \\
\hline & Post & .4712 & \pm & .03731 & Pre-Follow up & -.00976 & .08317 & -.829 & 0.411 \\
\hline & $\begin{array}{l}\text { Follow } \\
\text { up }\end{array}$ & .4960 & \pm & .08517 & $\begin{array}{l}\text { Post-Follow } \\
\text { up }\end{array}$ & .02476 & .08154 & 2.147 & 0.037 \\
\hline
\end{tabular}

Table 12:-Distribution of the studied nurses in relation to their mean score of nurse's performance subscale (accepting patients) skill pre, post, and follow up of the implementation of the training program.

\begin{tabular}{|c|c|c|c|c|c|c|c|c|c|}
\hline \multirow{2}{*}{\multicolumn{2}{|c|}{$\begin{array}{c}\text { Items of } \\
\text { performance }\end{array}$}} & \multirow{2}{*}{\multicolumn{3}{|c|}{ Plos }} & \multirow{3}{*}{ Comp. } & \multirow{2}{*}{\multicolumn{2}{|c|}{ Difference }} & \multirow{2}{*}{\multicolumn{2}{|c|}{ Paired T-test }} \\
\hline & & & & & & & & & \\
\hline & & Mean & \pm & SD & & Mean & SD & $\mathbf{T}$ & P-value \\
\hline \multirow{3}{*}{$\begin{array}{l}\text { Accept } \\
\text { patient }\end{array}$} & Pre & .2343 & \pm & .21744 & Pre-Post & .61714 & .26205 & .54267 & 0.00 \\
\hline & Post & .8514 & \pm & .15798 & Pre-Follow up & .40286 & .23213 & -.29803 & 0.00 \\
\hline & $\begin{array}{c}\text { Follow } \\
\text { up }\end{array}$ & .6371 & \pm & .30161 & $\begin{array}{c}\text { Post-Follow } \\
\text { up }\end{array}$ & -.21429 & .29468 & .33689 & 0.00 \\
\hline
\end{tabular}

Table 13:-Distribution of the studied nurses in relation to their mean score of nurse's performance subscale (therapeutic communication)skill pre, post , and follow up of the implementation of the training program 


\begin{tabular}{|c|c|c|c|l|c|c|c|c|c|}
\hline \multicolumn{2}{|c|}{ Items of performance } & \multicolumn{2}{|c|}{ Comp. } & \multicolumn{2}{c|}{ Difference } & \multicolumn{2}{c|}{ Paired T-test } \\
\cline { 2 - 9 } & Mean & \pm & SD & & Mean & SD & T & $\begin{array}{c}\text { P- } \\
\text { value }\end{array}$ \\
\cline { 3 - 9 } & Pre & .2942 & \pm & 07505 & Pre-Post & .31758 & .13689 & 16.405 & 0.000 \\
$\begin{array}{c}\text { Therapeutic } \\
\text { communication }\end{array}$ & Post & .6117 & \pm & .12266 & $\begin{array}{c}\text { Pre-Follow } \\
\text { up }\end{array}$ & .19899 & .10364 & -5.986 & 0.000 \\
\cline { 2 - 9 } & $\begin{array}{c}\text { Follow } \\
\text { up }\end{array}$ & .4931 & \pm & .11517 & $\begin{array}{c}\text { Post-Follow } \\
\text { up }\end{array}$ & -.11860 & .14010 & 13.577 & 0.000 \\
\hline
\end{tabular}

Table 14:-Distribution of the studied nurses in relation to their mean score of nurses' performance subscale (early detection of suicide attempts) skill pre, post , and follow up of the implementation of the training program.

\begin{tabular}{|c|c|c|c|c|c|c|c|c|c|}
\hline \multirow{2}{*}{\multicolumn{2}{|c|}{$\begin{array}{c}\text { Items of } \\
\text { performance }\end{array}$}} & \multirow{3}{*}{$\begin{array}{l}\text { Mean } \\
.0743\end{array}$} & \multirow{3}{*}{$\begin{array}{l} \pm \\
\pm\end{array}$} & \multirow{3}{*}{$\begin{array}{l}\text { SD } \\
.08773\end{array}$} & \multirow{3}{*}{\begin{tabular}{|l} 
Comp. \\
Pre-Post
\end{tabular}} & \multicolumn{2}{|c|}{ Difference } & \multicolumn{2}{|c|}{ Paired T-test } \\
\hline & & & & & & \multirow{2}{*}{$\begin{array}{l}\text { Mean } \\
.50000\end{array}$} & \multirow{2}{*}{$\begin{array}{c}\text { SD } \\
.23492\end{array}$} & \multirow{2}{*}{$\begin{array}{c}\mathbf{T} \\
15.050\end{array}$} & \multirow{2}{*}{$\begin{array}{r}\text { P-value } \\
0.000\end{array}$} \\
\hline Early & Pre & & & & & & & & \\
\hline of suicide & Post & .5743 & \pm & .23177 & Pre-Follow up & .28571 & .26452 & -5.935 & 0.000 \\
\hline & $\begin{array}{c}\text { Follow } \\
\text { up }\end{array}$ & .3600 & \pm & .28018 & $\begin{array}{c}\text { Post-Follow } \\
\text { up }\end{array}$ & -.21429 & .25531 & 7.638 & 0.000 \\
\hline
\end{tabular}

Table 15:-Distribution of the studied nurses in relation to their mean score of nurses' performance subscale ( safe environment) skill pre, post , and follow up of the implementation of the training program.

\begin{tabular}{|c|c|c|c|c|c|c|c|c|c|}
\hline \multicolumn{2}{|c|}{ Items of performance } & & & & \multirow[t]{2}{*}{ Comp. } & \multicolumn{2}{|c|}{ Difference } & \multicolumn{2}{|c|}{ Paired T-test } \\
\hline & & Mean & \pm & SD & & Mean & SD & $\mathbf{T}$ & $\begin{array}{c}P- \\
\text { value }\end{array}$ \\
\hline \multirow{3}{*}{$\begin{array}{c}\text { Safe } \\
\text { environment }\end{array}$} & Pre & .1733 & \pm & .17911 & Pre-Post & .26016 & .26016 & 17.332 & 0.000 \\
\hline & Post & .6044 & \pm & .17911 & $\begin{array}{c}\text { Pre-Follow } \\
\text { up }\end{array}$ & .27667 & .20373 & 9.602 & 0.000 \\
\hline & $\begin{array}{c}\text { Follow } \\
\text { up }\end{array}$ & .4500 & \pm & .26016 & $\begin{array}{c}\text { Post-Follow } \\
\text { up }\end{array}$ & .27667 & .20373 & -7.545 & 0.000 \\
\hline
\end{tabular}

Table 16:-Distribution of the studied nurses in relation to their mean score of nurses' performance subscale (help patient to cope) skill pre, post , and follow up of the implementation of the training program.

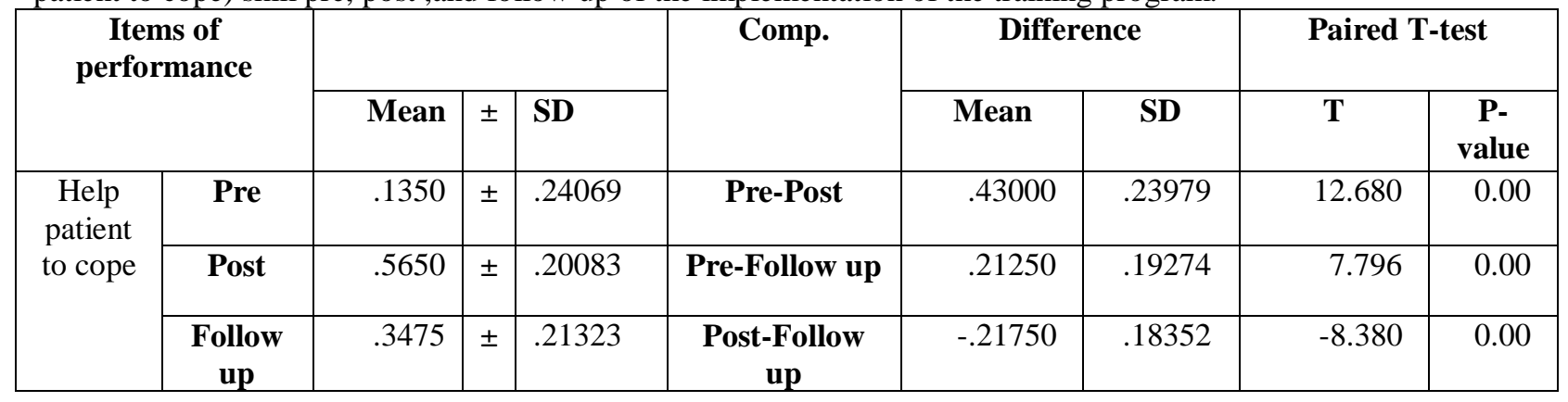

Table 17:-Distribution of the studied nurses in relation to their mean score of nurses' performance subscale (promote self esteem) skill pre, post, and follow up of the implementation of the training program.
Items of performance
Comp.
Difference
Paired T-test 


\begin{tabular}{|c|c|c|c|l|l|c|c|c|c|}
\hline \multicolumn{2}{|c|}{} & Mean & \pm & SD & & Mean & SD & T & P-value \\
\hline $\begin{array}{c}\text { Promote } \\
\text { self } \\
\text { esteem } \\
\text { and hope }\end{array}$ & Pre & .0914 & \pm & .15745 & Pre-Post & .40857 & .20613 & 14.015 & 0.000 \\
\cline { 2 - 9 } & $\begin{array}{c}\text { Follow } \\
\text { up }\end{array}$ & .5000 & \pm & .21258 & Pre-Follow up & .18000 & .16782 & 7.584 & 0.000 \\
\hline
\end{tabular}

Table 18:-Distribution of the studied nurses in relation to their mean score of nurses' performance subscale (change patient negative thoughts) skill pre, post , and follow up of the implementation of the training program.

\begin{tabular}{|c|c|c|c|c|c|c|c|c|c|}
\hline \multicolumn{2}{|c|}{$\begin{array}{c}\text { Items of } \\
\text { performance }\end{array}$} & \multirow[b]{2}{*}{ Mean } & \multirow[b]{2}{*}{ \pm} & \multirow[b]{2}{*}{ SD } & \multirow[t]{2}{*}{ Comp. } & \multicolumn{2}{|c|}{ Difference } & \multicolumn{2}{|c|}{ Paired T-test } \\
\hline & & & & & & Mean & SD & $\mathbf{T}$ & $\begin{array}{c}\text { P- } \\
\text { value }\end{array}$ \\
\hline \multirow{3}{*}{$\begin{array}{c}\text { Change } \\
\text { patient } \\
\text { negative } \\
\text { thoughts }\end{array}$} & Pre & .0300 & \pm & .07292 & Pre-Post & .51000 & .21405 & 16.848 & 0.00 \\
\hline & Post & .5400 & \pm & .20909 & Pre-Follow up & .29000 & .20429 & 10.038 & 0.00 \\
\hline & $\begin{array}{c}\text { Follow } \\
\text { up }\end{array}$ & .3200 & \pm & .21518 & $\begin{array}{c}\text { Post-Follow } \\
\text { up }\end{array}$ & -.22000 & .20876 & -7.452 & 0.00 \\
\hline
\end{tabular}

Table 19:-Distribution of the studied nurses in relation to their mean score of nurses' performance subscale (promote social interaction) skill pre, post, and follow up of the implementation of the training program.

\begin{tabular}{|c|c|c|c|c|c|c|c|c|c|}
\hline \multirow{2}{*}{\multicolumn{2}{|c|}{$\begin{array}{c}\text { Items of } \\
\text { performance }\end{array}$}} & \multirow[b]{2}{*}{ Mean } & \multirow[b]{2}{*}{ \pm} & \multirow[b]{2}{*}{ SD } & \multirow[t]{2}{*}{ Comp. } & \multicolumn{2}{|c|}{ Difference } & \multicolumn{2}{|c|}{ Paired T-test } \\
\hline & & & & & & Mean & SD & $\mathbf{T}$ & P-value \\
\hline \multirow{3}{*}{$\begin{array}{c}\text { Promote } \\
\text { social } \\
\text { interaction }\end{array}$} & Pre & .1225 & \pm & .19803 & Pre-Post & .51000 & .24333 & 14.820 & 0.000 \\
\hline & Post & .6325 & \pm & .23064 & Pre-Follow up & .35500 & .22779 & 11.020 & 0.000 \\
\hline & $\begin{array}{c}\text { Follow } \\
\text { up }\end{array}$ & .48 & \pm & .231 & $\begin{array}{c}\text { Post-Follow } \\
\text { up }\end{array}$ & -.15500 & .21512 & -5.095 & 0.000 \\
\hline
\end{tabular}

Table 20:-The effect of training programs on the total mean score of studied nurses' performance pre, post ,and follow up of the implementation of the training program.

\begin{tabular}{|c|c|c|c|c|c|c|c|c|c|}
\hline \multicolumn{2}{|c|}{ Items } & \multirow[b]{2}{*}{ Mean } & \multirow[b]{2}{*}{ \pm} & \multirow[b]{2}{*}{ SD } & \multirow[t]{2}{*}{ Comp. } & \multicolumn{2}{|c|}{ Difference } & \multicolumn{2}{|c|}{ Paired T-test } \\
\hline & & & & & & Mean & SD & $\mathbf{T}$ & $\begin{array}{c}\text { P- } \\
\text { value }\end{array}$ \\
\hline \multirow{3}{*}{$\begin{array}{c}\text { Total } \\
\text { performance } \\
\text { score }\end{array}$} & Pre & 14.4373 & \pm & 11.03578 & Pre-Post & 46.55512 & 12.64510 & 14.820 & 0.000 \\
\hline & Post & 60.9925 & \pm & 12.57687 & $\begin{array}{c}\text { Pre-Follow } \\
\text { up }\end{array}$ & 27.52155 & 9.94339 & 11.020 & 0.000 \\
\hline & $\begin{array}{c}\text { Follow } \\
\text { up }\end{array}$ & 41.9589 & \pm & 16.47868 & $\begin{array}{c}\text { Post-Follow } \\
\text { up }\end{array}$ & $\begin{array}{r}- \\
19.03358\end{array}$ & 10.39732 & -5.095 & 0.000 \\
\hline
\end{tabular}

Table 21:-Relation between the total nurse's knowledge score and demographic data.

\begin{tabular}{|r|r|r|r|}
\hline \multicolumn{1}{|c|}{ Characteristics } & Mean+SD & \multicolumn{1}{|c|}{$\mathbf{Z}$} \\
\hline Age in years: & & 0.011 & 0.993 \\
\hline$<30$ & $52.13+4.21$ & & \\
\hline Sex: & $52.77+6.60$ & & \\
\hline
\end{tabular}




\begin{tabular}{|r|r|r|r|}
\hline Males & $53.58+4.14$ & & \\
\hline Females & $52.26+6.43$ & & \\
\hline Marital status & & 0.486 & 0.627 \\
\hline Currently not married & $52.50+5.32$ & & \\
\hline Residence: & $52.60+6.16$ & & \\
\hline Urban & $52.41+5.55$ & & \\
\hline Rural & $52.67+6.23$ & & \\
\hline Educational level: & & 1.036 & 0.596 \\
\hline Nursing diploma & $52.52+5.09$ & & \\
\hline Bachelor of nursing & $54.42+8.14$ & & \\
\hline Experience in years & $51.35+5.12$ & & \\
\hline $1-5$ & & 2.430 & \\
\hline $6-10$ & $54.71+6.19$ & & \\
\hline$>10$ & $51.63+5.57$ & & \\
\hline Secondary school of nursing & $51.85+5.57$ & & \\
\hline Pes & & 0.820 & \\
\hline Po & $54.15+7.08$ & & \\
\hline
\end{tabular}

Table 22:-Relation between the total nurses' performance score and demographic data

\begin{tabular}{|r|r|r|c|}
\hline Characteristics & Mean+SD & $\mathbf{Z} / \mathbf{X}^{2}$ & $\mathbf{P}$ \\
\hline Age in years: & $13.07+6.79$ & 0.925 & 0.355 \\
\hline$<30$ & $15.46+8.95$ & & \\
\hline Sex: & & 0.080 & 0.936 \\
\hline Males & $14.90+7.55$ & & \\
\hline Females & $14.68+8.70$ & & \\
\hline Marital status & $18.90+10.49$ & & \\
\hline Currently married & $13.70+7.55$ & & \\
\hline Residence: & & 1.369 & 0.071 \\
\hline Urban & $16.29+8.15$ & & \\
\hline Rural & $13.94+8.48$ & & \\
\hline Educational level: & & 5.187 & \\
\hline Nursing diploma & $12.33+7.53$ & & \\
\hline Bachelor of nursing & $17.92+5.21$ & & \\
\hline Experience in years & $15.47+10.44$ & & \\
\hline $1-5$ & & 5.810 & \\
\hline $6-10$ & $14.00+9.15$ & & \\
\hline$>10$ & $19.25+9.86$ & & \\
\hline Secondary school of nursing & $11.65+4.33$ & & \\
\hline Previous training & & 0.122 & 0.903 \\
\hline No & $14.62+9.42$ & & \\
\hline
\end{tabular}

Table 23:-Correlation between the total performance score and total knowledge score

\begin{tabular}{|c|c|c|}
\hline Correlation & $\mathrm{R}$ & Performance \\
\hline Knowledge & 0.172 & $\mathrm{P}$ \\
\hline Before intervention & 0.285 & 0.233 \\
\hline Immediately after & 0.365 & $0.045^{*}$ \\
\hline After three month & & $0.009^{*}$ \\
\hline
\end{tabular}




\section{Discussion:-}

Nurses assessed patients' suicide risk through vigilant observation, recognizing warning signs, using their interviewing skills and gathering information about cues to suicide. Assessing the patients continuously throughout the hospital stay seems important to capture the patient's changing state of mind. However, some nurses are not properly qualified to intervene for suicidal patients. So the aim of this study was to determine the effect of this psycho-educational program about control of suicidal ideation among psychotic patients on a nursing staff's knowledge and practice at Tanta Psychiatric and Mental Health hospital. ${ }^{(29-32)}$

The suicide-based training program in this study monitored two dimensions namely knowledge about suicide and nursing-practices to intervene a suicide. Concerning the level of knowledge about suicide, more than half of nurses showed a poor level before implementing training program. Such a result can be relatively understood in the light of the fact that there is lack of educational courses about suicide provided by hospital for nurses. This may be also due to , most of the studied nurses had an age range between 30to 40 years, nearly half of them in the current study had a nursing diploma had graduated years previous and may have forgotten information they had once studied about suicide. While a study done by Taha E, (2012) at Mansoura about effect of an educational program for the psychiatric nurses on their knowledge and attitude toward suicidal patients found that nurses with a low level of knowledge about suicide before implementing training $\operatorname{program}^{(19)}$.

In the present study, it was observed that there was a significant difference improvement in total level of nurse's knowledge about suicide immediately after the educational program. Such a result is supported by research evidences which indicates that nurses are able and willing to learn and understand information that improves their suicide intervention with patients through a training program. The researcher observed that the nurses during sessions were very interested and had the desire to know every thing about suicide as they mentioned that this will help them in their personal or professional life. This result was supported by a study conducted by Giordano \& Stichler,( 2009) in California that involved the development of an educational module to enhance nurses' knowledge and skills in suicide prevention, Findings revealed a significant improvement pre- and immediate post- test in nurses' knowledge and skills in suicide prevention with overall improvement in the nurses' ability to identify and intervene to prevent an act of suicide. ${ }^{(33)}$ It is important to note that while most studies show evidence that training increases knowledge, at least one study found no such effect. Specifically, Mishara, Houle, and Lavoie (2005) found that training did not significantly improve knowledge about suicide or the utilization of resources for gatekeepers or the suicidal individual six months after the training. ${ }^{(34)}$

It was observed also that the educational programs were more effective immediately after than at follow up. This was because strategies to maintain improvement were not implemented, nor was maintenance investigated, either at al or for long-term. Another explanation is time factor since the final assessment was after three months and the nurses didn't try to maintain their improved knowledge through frequent reading. This likes a,- study conducted by (-Kishi et al-,(2014), where results showed improvement in nurse's knowledge about suicide in immediate posttest ,but this improvement was not maintained after one month of the program ${ }^{(35)}$ In contrast to the study conducted by -(Tsai et al,-( 2011) the result revealed that immediately after the training the nurses were much more aware of suicide warning signs and more willing to refer patients for professional counseling. (19)

The present study showed that the total mean score of nurse's knowledge about their role in suicide prevention improved after the educational program. This may be because the researcher introduced to various videos about nursing roles, distributed clinical situation to nurses after sessions, which helped nurses capture this knowledge more easily. The study conducted by (Abigail M. Kotowski,-( 2015)- in New York, revealed improvement of knowledge of nurses' different variables including nursing roles to intervene with suicidal patients. ${ }^{(36)}$

Regarding the second target dimension of the training program in the present study, nursing practice ,the studied nurses exhibited very low or low level of skills before intervention. It is important here to say that the poor level of knowledge, which nurses had, before the program was a negative effect on their practice. Another rationale for this result may be that the majority of the studied nurses were acquired either diplomas or secondary schools of nursing degrees and ,needless to say, that the psychiatric nursing courses in these programs in general are relatively concise and ignore training about suicide skills because of its allotted time and content. This stated decrement of their skill due to lack of both knowledge and training about suicide before graduation. ${ }^{(37,38)}$ 
Other assumptions from the studied nurses' perspectives for such deficiency in their skill was that; the educational courses they had, didn't focus on suicide specifically and this program was the first training course for them about suicide skills alone. Or perhaps their negative belief about the importance of their role in intervening with suicidal patient, their fear of feeling or burnout, job dissatisfaction, or false belief that the suicidal patient may be dangerous. Additionally, it has been observed that the nursing practices in psychiatric hospitals were focused on the medical care only and carried out in the form of routine duties or practices, instead of individualized care that is based on a problem-solving approach in accordance with patient needs.

The enhancement of nursing skills was remarkable in the results of the current study; this may be due to practical sessions which allowed nurses to effectively practice suicide intervention skills over a period of time via simulated clinical situations, as well as role play sessions which allowed nurses to re-demonstrate important skills and receive feedback from researchers. This method also helped the nurses know how they can convey the appropriate response when intervening with suicidal patients .In this line, Paun and Griffin,( 2011 ) conducted suicide prevention training program pre training, one month after, and at three months after examining suicide-related knowledge and prevention skills, Results showed significant increases in suicide intervention skills ,as well as confidence in responding to and interacting with the suicidal person. ${ }^{(39)}$

For measuring the level of skills after three months, it was noticed that there was a decline from a very high level to a high level. This may be due to that the fact that intervention skills-decline with time, especially at the hospitals where there was no training for this skill. This was contradicted by (Oordt, Jobes, \& Schmidt,( 2009) who observed mental health professionals changing suicide care practices in response to the training, and these results persisted after a 6 month follow-up. ${ }^{(40)}$

Regarding the relationship between the total knowledge - score about suicide and their skills after applying the program, the present study showed a significant relation between them in study. This indicates willingness of nurses to understand any information that improves their skills and delivering of high quality of care to suicidal patient Such a result supported the efficacy of the training program which was systematic and understandable ,in contrast to-David J (2007) who investigated the relationship between knowledge of suicide and the capacity to respond appropriately to suicidal people. The resulting lack of association between the two variables suggests they are independent, with both potentially important suicide prevention competencies. ${ }^{(41)}$

Many researchers have asserted that socio-demographic variables of nurses may affect their knowledge about suicide. This was inconsistent with the current results which revealed that no significant statistical difference were found between demographic data and total knowledge scores. Aseltine and colleagues (2007) also found that the effect of training on suicide knowledge, attitudes and, intervention skills at three-months post-training did not differ according to sex. ${ }^{(42)}$ Additionally, this study contradicted a study conducted by Clark, (2010) which revealed that females appeared to be more knowledgeable, have more adaptive beliefs, and be more likely to intervene than males both before and after receiving suicide training. ${ }^{(43,44)}$

In the final analysis, the findings indicated that experienced mental health nurses may have an important role in preventing suicidal acts/self-harm among patients. It is crystal clear that psycho-educational programs increase knowledge, and skills of studied nurses .Therefore, continuing education, training and support for nurses in their work with patients at risk for suicide should be implemented regularly by hospitals to maintain further increased suicide interventions skills of nurses, so that nurses can develop therapeutic attitudes and responses towards patients at risk for suicide and provide helpful care.

\section{Conclusion:-}

Based on the results of the present study, It can be concluded that a marked increase in the overall knowledge and skills of the studied nurses as the result of receiving an educational program about control of suicidal ideation among psychotic patients on nursing staff's knowledge and practice 


\section{Recommendations:-}

In the light of the result of this study the following recommendations are suggested Recommendations related to patients:

1. Psycho-educational sessions about control of suicidal ideation should be provided in a treatment program during patients' hospitalization.

2. Cognitive behavioral sessions to modify suicidal ideas among high risk suicidal patients .

3. Health education about different coping strategies to deal with suicidal ideas when rehabilitating the patients to the community

Recommendations related to patients' family:

Developing and implementing educational programs for psychiatric patients' families about how to deal with patients having suicidal ideation..

Recommendations related to hospital staff:

Health care providers must learn to work with patients through positive therapeutic relationships and use communication skills to encourage patients to express their experiences about their suicide idea or attempt and verbalizing if they feel unwell.

\section{References:-}

1. Kneisl, C R., \&Trigoboff E. Pearson New International Edition: Contemporary Psychiatric - Mental Health Nursing, $3^{\text {rd }}$ ed, United States of America, Pearson Co., 2014;183-85.

2. Sadock ,B \&SadockV .Kaplan and Sadock's Concise Textbook of Clinical Psychiatry, $3^{\text {rd }}$ ed,Philadelphia: Lippincott Williams \&Wilkins Co.,2008;428.

3. Gould M, Greenberg T, Velting D\& Shaffer D. Youth suicide: A review. The Prevention Researcher .Psychosocial nursing Journal 2006;13(3):2-7.

4. Blackmore E, Munce S, Weller I . Psychosocial and clinical correlates of suicidal acts results from a national population survey. British Journal of Psychiatry 2009;19(2):279-284.

5. TripodiA\& Bender G. Factors associated with suicide attempts by older adults: A prospective study. American Journal of Psychiatry 2006; 15(2): 1687-1692.

6. Ghio L, Zanelli E, Gotelli $\mathbf{S} \&$ Gabrielli $\mathbf{F}$. Involving patients who attempt suicide in suicide prevention: A focus groups study. Journal of Psychiatric and Mental Health Nursing 2011; 18(2): 510-518.

7. Botiga N ,Silva Sand Reginato D. Maintained attitudinal changes in nursing personnel after brief training on suicide prevention .Journal of Social Psycholoy 2015;37(3):145.

8. Katsuki A, Fujika M, Masahiro G\& Toshiyuki S. A study of emotional attitude of psychiatric nurses: Reliability and validity of the Nurse Scale. International Journal of Mental Health Nursing 2014; 12(2): 265270.

9. Mohr W .Psychiatric mental Health Nursing, $7^{\text {th }}$ ed ,London Lippincott Williams \&Wilkins Co.,2009;740-45.

10. Pompili M, Amador X \&Giradi P. Suicide prevention and the broad spectrum approach to health promotion. Health Education Research;19(4):476-48.

11. Betz M, Sullivan A, Manton P, Espinola J\& Boudreaux $\mathbf{E}$.Knowledge, attitudes and practice of emergency department providers in the care of 2013; 30(5): 1005-1012.

12. Mccann T, Clark E, McConnachie S\& Harvey I. Accident and emergency nurses attitudes towards patients who self-harm. Accident and Emergency Nursing 2006; 14(3): 4-10.

13. Scheckel M \&Nelson K. A interpretive study of nursing students' experiences of caring for suicidal persons. Journal of Professional Nursing 2014; 30(5):426-435 .

14. Cheryl P, Janet Y, Barbara L\& Pamela G .Competency based training for nurse generalists: inpatient intervention and prevention of suicide .Journal of the American Psychiatric Nurses Association 2013;19(4): 209-300.

15. Kishi Y Otsuka K, Akiyama $\mathbf{K}$,YamadaT \&ThurberS. Effects of a training workshop on suicide prevention among emergency room nurses. Journal of Psychiatric and Mental Health Nursing. 2010 ;35 (5):357-361.

16. Kerkhof J. Improving the application of a practice guideline for the assessment and treatment of suicidal behavior by training the full staff of psychiatric departments. Hong Kong Nursing Journal 2008; 15 (3):452-59 .

17. Gibb B, Chan S, Chien W, \&Tso $\mathbf{S}$. The qualitative evaluation of a suicide prevention and management programme by general nurses. Journal of Clinical Nursing 2009; 17(6):2884-2894.

18. Anderson M. Nurses' attitude toward suicidal behavior-a comparative study of community mental health nurses and nurses working in an emergency department .Journal of advanced Nursing 2006;24(2):1293-99 . 
19. Taha S. Effect of an educational program for the psychiatric nurses on their knowledge and attitude toward suicidal patients .unpublished Master Thesis ,Mansoura University-Faculty of nursing 2012.

20. Morgan H. \& Priest P. Suicide and other unexpected deaths among psychiatric inpatients: The Bristol confidential inquiry. British Journal of Psychiatry 2011; 158(11): , 368-374.

21. Meehan J , Kapur N, Hunt I, Turnball P \& Appleby L. Suicide in mental health in-patients and within 3 months of discharge: National clinical survey .British Journal of Psychiatry 2007; 188(8): 129-134.

22. Nick W. An Introduction to Mental Health Nursing, $2^{\text {nd }}$ ed, United States of America, Bell \& Blain Glasgow Co., 2009;129-32.

23. Anthony H, Chris H. Mental Health Care for Nurses: Applying Mental Health Skills in the General Hospital, Firsted, Oxford, Blackwell Co.,2006;130-145.

24. Noreen C, Lawerence E .Psychiatric Mental Health Nursing, $3^{\text {rd }}$ ed, United States of America, Donelly, Willard Co., 2011;369-383.

25. MinnerJ.The experience of student nurses who are caring for patient at risk for suicide. unpublished Doctoral Thesis, Washington State University-Faculty of nursing 2015.

26. Clark, L. Watson, D. .Constructing validity: basic issues in objectives scale development. Psychol. Assess 11995;7,309-319.

27. -Holmbeck G. , Devine K Editorial :Anauthor's checklist for measure development and validation manuscripts .J. Pedia .Psychol 2009;34,691-696.

28. Peat A.Concept of validity" International Journal of Epidemiology. 2001;(31):1139-1144

29. Pisani A , Cross W \& Gould M. The assessment and management of suicide risk: State of workshop education. Suicide and Life-Threatening Behavior 2014 ; 41 (3), 255- 274.

30. Runeson B\& Asberg M. Family history of suicide among suicide victims. American Journal of Psychiatry 2013; 160(12): 1525-29.

31. Sun F Long A \&Boore J .Suicide: a literature review and its implications for nursing practice in Taiwan. Journal of Psychiatric and Mental Health Nursing 2015;12(2):474-79

32. Hendin H, Al Jurdi R, Houck P, Hughes S \& Turner J. Evidence for significant improvement in prediction of acute risk for suicidal behavior. Journal of Mental Disease 2014;198(8):604-615.

33. Giordano and J. F. Stichler, "Improving suicide risk assessment in the emergency department," Journal of Emergency Nursing 2009 (35): 22-26.

34. Mishara BL ${ }^{1}$, Houle J, Lavoie B.Comparison of the effects of four suicide prevention programs for family and friends of high-risk suicidal men who do not seek help themselves. Suicide Life Threat Behav 2005 J35(3):32942.

35. Kishi, Y., Otsuka, K., Akiyama, K., Yamada, T., Sakamoto, Y., Yanagisawa, Y., ... Thurber, S. (2014). Effects of a training workshop on suicide prevention among emergency room nurses. Crisis: The Journal of Crisis Intervention and Suicide Prevention 2014, 35(5), 357-361.

36. Abigail $\mathbf{K}$.Devlopment of Instructional Comptencies for Assessing and Managing Suicide Risk for Baccalaureate Nursing education .Unpuplished Doctoral thesis ,University of New York 2015

37. Gulfii , Green K, Allen J, Jobes D, \&Nadorff M. Collaborative assessment and management of suicidality in an inpatient setting: results of a pilot study. Psychiatric Nursing Journal 2012; 49(1):72-80

38. King K\& Vidourek R. Effective prevention and intervention strategies. The Prevention Researcher 2012; 19(4):15-17

39. -Griffin, D ,Indelicato, Natalie Arce; Mirsu-Paun, Anca;.Outcomes of a Suicide Prevention Gatekeeper Training on a University Campus Journal of College Student Development 2011 ;52(3) 350-361.

40. Oordt MS ${ }^{1}$, Jobes DA, Fonseca VP, Schmidt SM.Training mental health professionals to assess and manage suicidal behavior: can provider confidence and practice behaviors be altered. Suicide Life Threat Behav journal. 2009 39(1):21-32.

41. David J. Inman O , Wallace J \& Peggy A. The relationship between suicide knowledge and suicide interviewing skill.Death journal 8;2(3)

42. Aseltine ., and DeMartino R., "An Outcome Evaluation of the SOS Suicide Prevention Program," American Journal of Public Health 200;. 94(3). 446-451.

43. Clark R., Matthieu M., Ross A, and Knox L., "Training Outcomes from Samaritans of New York Suicide Awareness and Prevention Programme Among Community- and School-Based Staff," British Journal of Social Work 22010 ; 40(7) 2223-2238.

44. Aflague $\mathbf{J}$ \&Ferszt $\mathbf{G}$.A suicide assessment by psychiatric nurses: A phenomenographic study. Issues in Mental Health Nursing 2010; 31(6):256 